\title{
Primary Thyroid Malignancies in Tehran, Iran
}

\author{
Bagher Larijani $^{\mathrm{a}}$ Mohammad Ali Mohagheghi ${ }^{\mathrm{b}}$ \\ Mohammad Hassan Bastanhagh ${ }^{\mathrm{a}}$ Ali Reza Mosavi-Jarrahi ${ }^{\mathrm{b}, \mathrm{c}}$ \\ Vahid Haghpanah $^{\mathrm{a}}$ Seyed Mohammad Tavangar ${ }^{\mathrm{d}}$ Fatemeh Bandarian $^{\mathrm{a}}$ \\ Nasim Khaleghian ${ }^{a}$ \\ ${ }^{a}$ Endocrinology and Metabolism Research Centre, Tehran University of Medical Sciences, ${ }^{b}$ The Cancer Institute \\ Research Centre, Imam Khomeini Medical Centre, Tehran University of Medical Sciences, ${ }^{\mathrm{C}}$ Department of Social \\ Medicine, Medical School, Shahid Beheshti University of Medical Sciences, and ${ }^{d}$ Department of Pathology, \\ Shariati Hospital, Tehran University of Medical Sciences, Tehran, Iran
}

\section{Key Words}

Cancer registry · Thyroid cancer · Epidemiology • Survival

\begin{abstract}
Objective: The aim of this study was to present a descriptive epidemiology of primary thyroid cancer in Tehran, Iran, using cancer registry data. Subjects and Methods: All cases of thyroid cancer registered from 1998 to 2001 in Tehran Metropolitan Area Population-Based Cancer Registry were used for this study. The incidence of thyroid cancer was estimated for the area covered by the cancer registry. Survival of patients was ascertained by telephone call to the patients or the patient's family and/ or linkage of registry data to mortality data from the Bureau of Vital Statistics. Patient's survival was based on sex, age and morphological type of tumour. Results: Four hundred and twenty-nine cases of primary thyroid cancer were registered in the Tehran Metropolitan Area Cancer Registry. The incidence of thyroid cancer was 3.5 and 1.0 per 100,000 population per year for females and males, respectively. Seventy percent of tumours were papillary, $11 \%$ follicular, $6.2 \%$ medullary, and the rest
\end{abstract}

were other subtypes. The papillary and follicular variants occurred in younger age: $43 \pm 16$ and $46 \pm 13$ years, respectively; the medullary and anaplastic variants occurred in older age: over 50 years. A 5-year survival rate was $82.2 \%$, with median survival of 66 months and $95 \%$ confidence interval of 63 and 69 months. Men and women had a similar survival experience. Conclusions: While the incidence of thyroid cancer was slightly high, the descriptive epidemiology of thyroid cancer in Tehran did not manifest a unique feature. Tehran patients experienced a high rate of survival, and the survival time for males and females was similar.

Copyright (C) 2005 S. Karger AG, Basel

\section{Introduction}

Thyroid cancer is the most common endocrine malignancy, with worldwide incidence rates generally lower than 3 per 100,000 for men and 5 per 100,000 for women [1-3]. Thyroid cancer has four main histological types: papillary, follicular, medullary and anaplastic. Papillary cancer is the most prevalent type, and is three times more common in women than men [2, 4]. There are also marked

\section{KARGER}

Fax +4161306 1234

E-Mail karger@karger.ch

www.karger.com
C 2005 S. Karger AG, Basel

$1011-7571 / 05 / 0146-0396 \$ 22.00 / 0$

Accessible online at:

www.karger.com/mpp
Bagher Larijani, MD

Endocrinology and Metabolism Research Centre

5th Floor, Shariati Hospital, North Kargar Avenue

Tehran 14114 (Iran)

Tel. +98 218026902 - 3, Fax +98 21802 9399, E-Mail emrc@sina.tums.ac.ir 
geographic, ethnic, and temporal variations in incidence rates [3]. Genetic and environmental factors play a key role in modulating thyroid cancer pathogenesis [3]. Longitudinal data from population-based registries show that the incidence of papillary thyroid cancer has increased up to fivefold in a number of countries over the past 60 years [4-6]. Thyroid cancer shows considerable ethnic and geographic variation, and high incidence rates are reported in areas of high iodine intake [7]. The prognosis for thyroid cancer is very good especially in developed countries where 5-year survival rates exceed 90\%. An improved prognosis of thyroid cancer is reported in regions of adequate dietary intake of iodine compared with regions where goitre is endemic, perhaps because of the higher incidence of undifferentiated thyroid cancer in iodinedeficient areas $[8,9]$. The epidemiology of thyroid cancer has not been comprehensively investigated in Iran. Goitre had been endemic in Iran; however, due to iodine supplementation, the prevalence of goitre has decreased $[10,11]$. The objective of this study was to utilize thyroid cancer data from Tehran Metropolitan Area PopulationBased Cancer Registry to describe the epidemiology of thyroid cancer in Tehran.

\section{Subjects and Methods}

Data regarding all cases of thyroid cancer registered from 1998 to 2001 were obtained from the Tehran Metropolitan Area Cancer Registry (TMACR). A full description of the TMACR has been published in our descriptive analysis of the data [12]. Briefly, the TMACR is a collaborative program of the Cancer Institute Research Centre and the International Agency for Research on Cancer, Lyon, France. The registry is funded by different research centres in Tehran, including Endocrinology and Metabolism Research Centre (EMRC) and Tehran University of Medical Sciences. The incidence of thyroid cancer was estimated based on data from the year 1998 for the covered area after excluding referrals and duplicate registries. Data collection was complete for the year 1998 but not for other 3 years. To calculate incidence, the estimated number of mid-year population in 1998 was obtained from the Bureau of Statistics, the details of methodology of the registry has been published separately [13]. All survival and all other analyses (excluding incidence) were based on the data in the cancer registry database including referrals. The survival status of each patient was ascertained by telephone call to the patient or the patient's family or/and linkage of registry data to mortality data from the Bureau of Statistics. Two telephone attempts were made for each patient. One call was made during office hours, and if this call was not successful, another attempt was made at night. The calls were made in October 2003. For the linkage of registry data to mortality data a previously developed linkage strategy [14] was used. Kaplan Meier survival function was used to describe the survivals, and log-rank test was used to compare the survival experiences of patient subgroups. All analyses were performed using SPSS software, version 10.01.

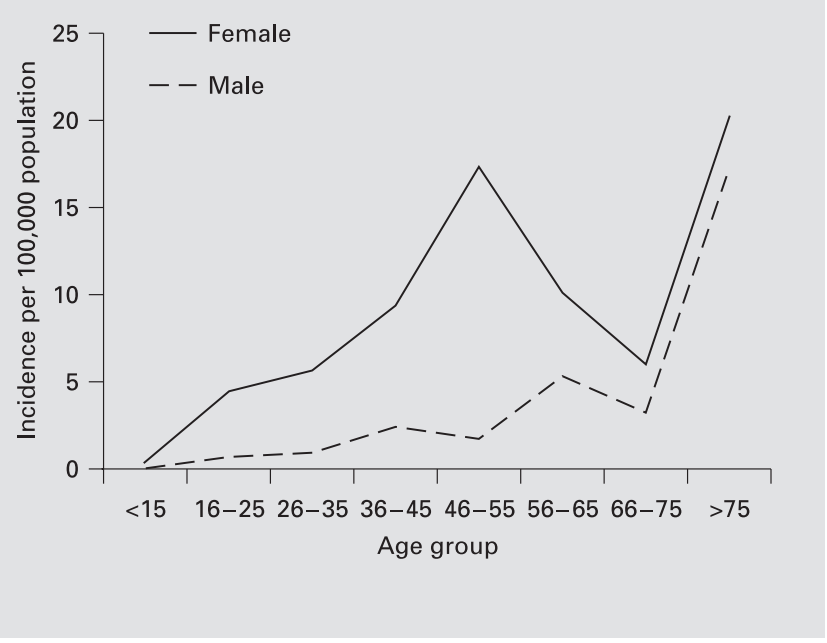

Fig. 1. Age-specific incidence of thyroid cancer by gender (Tehran metropolitan area).

\section{Results}

A total of 429 cases of thyroid cancer were registered in the 1998-2001 period. Of these, 355 belonged to the area covered by registry. Ninety-two percent of the cases had histopathologic verification of tumour and just $8 \%$ were diagnosed by other means (sonoimaging, clinical, or death certificates). Seventy-four percent of the cases were women and $26 \%$ men, resulting in a female: male ratio of $3: 1$. The annual crude incidence of thyroid cancer was estimated at 3.5 and 1.0 per 100,000 population for females and males, respectively. The incidence of thyroid cancer showed a different age distribution for males and females; for females the highest incidence was at 4555 years and for males at 55-65 years; the incidence increased after age 65 for both sexes (fig. 1). The most frequent morphologic variant was papillary carcinoma with a frequency of $69.9 \%$. The follicular, medullary and anaplastic variants were $13.5,4.7$ and $7.2 \%$, respectively. The papillary and follicular tumours occurred in younger patients $(43.1 \pm 17$ years for papillary and $46.0 \pm 13.0$ years for follicular), and medullary and anaplastic tumours occurred in the age group over 50 years (table 1). The distribution of the morphologic subtypes according to gender was the same for all subtypes with a female:male ratio of almost $3: 1$, except for the medullary tumours, which occurred more often in males than females: 1.9:1 (table 1). 


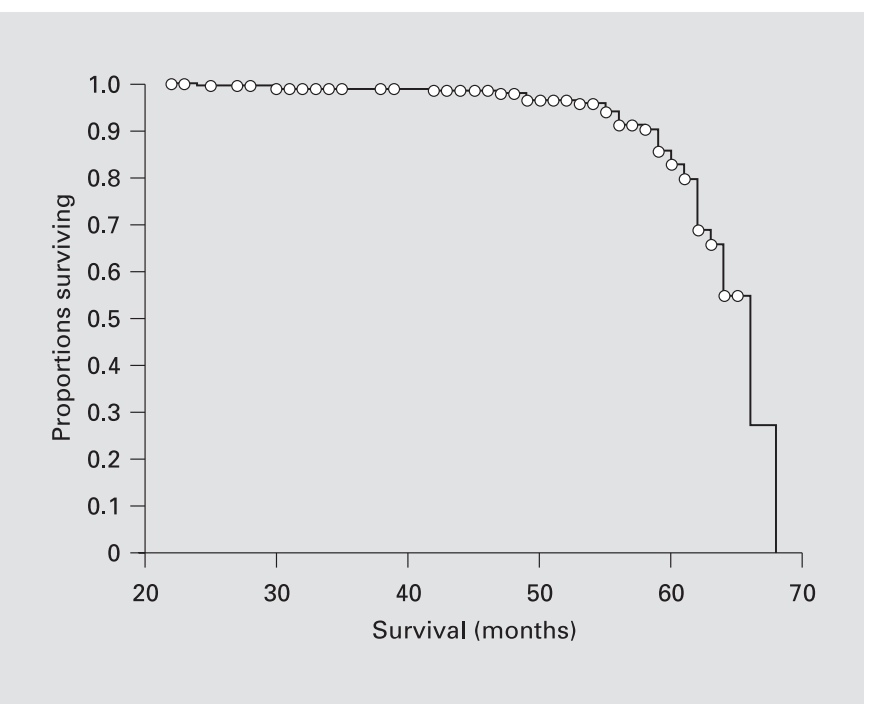

Fig. 2. Overall survival for thyroid patients.

Table 1. Distribution of age and sex for different tumour morphologies

\begin{tabular}{lrrr}
\hline Morphologic feature & \multicolumn{1}{l}{ Males } & \multicolumn{1}{l}{ Females } & Age, years \\
\hline Papillary & $75(25.0 \%)$ & $225(75.0 \%)$ & $43.1 \pm 16.7$ \\
Follicular & $15(22.4 \%)$ & $45(77.6 \%)$ & $46.0 \pm 12.7$ \\
Medullary & $13(65.0 \%)$ & $7(35.1 \%)$ & $55.8 \pm 22.3$ \\
$\begin{array}{l}\text { Anaplastic and } \\
\text { undifferentiated }\end{array}$ & $6(30.0 \%)$ & $14(70.0 \%)$ & $62.1 \pm 18.3$ \\
\hline
\end{tabular}

Values for age are expressed as mean \pm standard deviation.

Of the 429 registered cases, 307 had a telephone number in the database of the cancer registry. The two attempted calls showed a response rate of $62 \%$. For 125 cases, no survival status was ascertained due to either wrong telephone number $(27 \%)$ or the telephone number no longer existed in the telecommunication networks (12\%), leaving 182 cases for survival analysis. Linkage of registry to mortality data did not add any information to the data (no extra death was ascertained for linkage). During 5.5 years of follow-up, 31 deaths occurred among the patients. The overall survival function is presented in figure 2. Survival observed during 5 years was $82 \%$. The median survival was 66 months with $95 \%$ confidence interval of 63-69. Males and females had a similar survival experience (fig. 3). Survival function significantly dif-

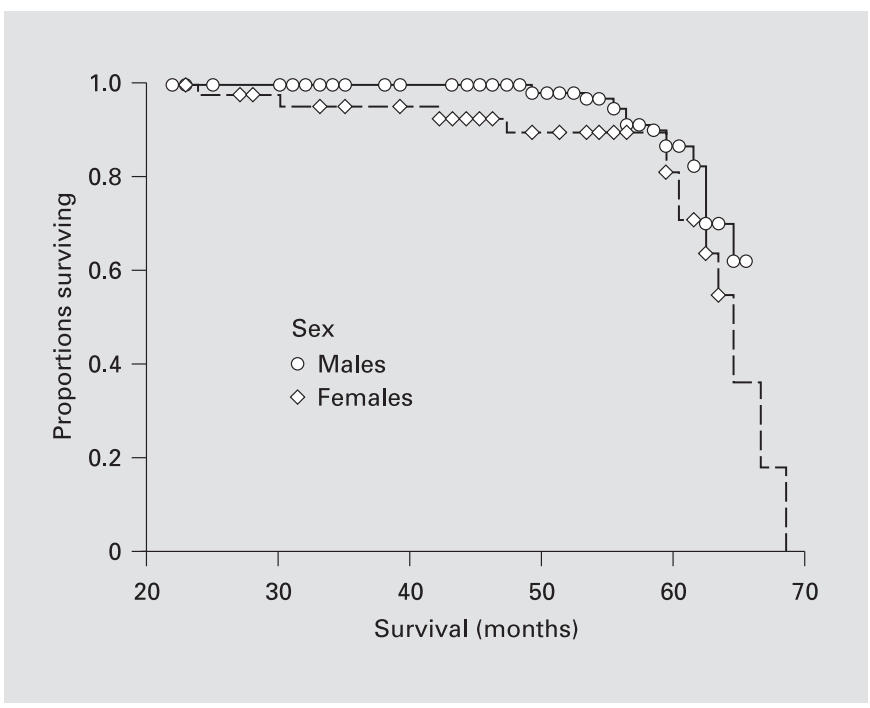

Fig. 3. Survival experience of thyroid cancer patients according to sex.

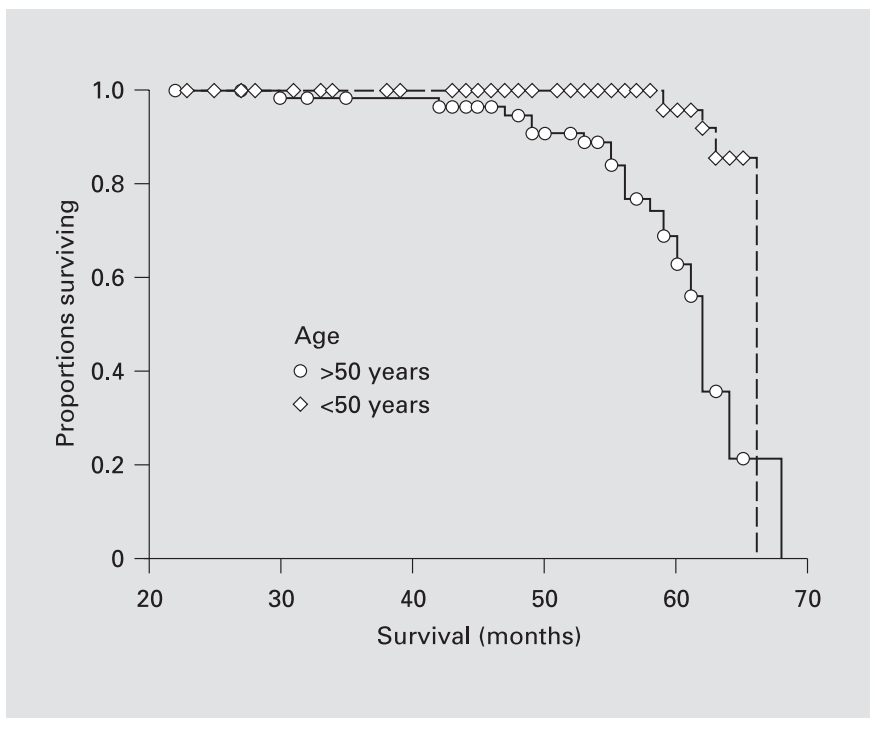

Fig. 4. Survival experience of thyroid cancer patients according to age at diagnosis.

fered $(p<0.001)$ according to age; after 4 years of similar survival experience, there were more deaths due to thyroid cancer in people over 50 years compared with people younger than 50 (fig. 4). No statistically significant difference in survival rates was seen among cases with a different histopathologic subtype of tumour; however, there were more deaths among patients with anaplastic tu- 
mours ( 3 out of 8 cases, $38 \%$ ) and medullary tumours (2 out of 7 cases, 28\%) as compared with papillary and follicular tumours (21 out of $165,12 \%)$.

\section{Discussion}

Cancers of the thyroid are relatively uncommon in different areas of the world. The epidemiologic features are well established and studied in most of the developed countries as well as in some developing countries. The incidence of thyroid cancer in this study is low, resembling the incidence reported by Iran's neighbouring countries (Kuwait, males: 3.2, females: 5; Bahrain, males: 3.2, females: 7.1) [15]. There has been no report of thyroid cancer incidence from other countries in the Middle East to date, but studies on immigrants in European countries indicate a higher incidence of thyroid cancer in Middle Eastern people compared with that of immigrants from other parts of the world [16].

A relatively elevated incidence of thyroid cancer in our population could easily be related to iodine deficiency as goitre is hyper-endemic in Iran (a large population-based study in 1980 reported a $50 \%$ prevalence of goitre in women and 40\% in men) [17]. However, there are conflicting reports regarding the association of iodine deficiency and goitre with thyroid cancer - there is a report of a positive association from Italy [18], and a contrasting report from USA and Nordic countries [19]. In addition, in the areas of endemic goitre, there are reportedly more follicular than papillary tumours. This contradicts our data in which $75 \%$ of tumours were papillary and just $11 \%$ follicular. A mass program of iodide supplementation has been implemented since 1983 in the country, and the result of this program has shown the prevalence of iodine deficiency was in fact reduced by $10 \%$, and $65 \%$ of the population tested had urinary iodine level between 10 and $25 \mathrm{mg} / \mathrm{dl}$ [11]. Improved iodine intake in previously iodine-deficient communities has also been associated with an increased incidence of papillary thyroid cancer [20, 21]. A higher frequency of papillary carcinoma in our study (in a population with hyper-endemic goitre) could be explained by improvement of iodine intake in the population after the iodine supplementation of 1983; though more rigorous studies are needed to confirm this observation.

Another established risk factor for thyroid cancer is ionising radiation either from artificial sources (especially medical sources such as diagnostic or therapeutic radiations) or natural sources (background radiation). The frequency of exposure to radiation from nuclear medicine procedures is very low in Iran with a prevalence of 1.9 per 1,000 of population [22]. There is an area of high background radiation in the northern part of Iran with radiation levels in some spots as high as $100 \mu \mathrm{Gy} \mathrm{h}^{-1}$ [21], but its contribution to cancer incidence especially to thyroid cancer would be negligible due to the small population exposed. The study of background radiation in other parts of Iran has shown even less than world average exposure to radiation $(48.3 \%$ of the world average total radiation background) [23]. Further epidemiological studies of risk factors of thyroid cancer are needed to explain the mildly elevated frequency of thyroid cancer in the Iranian population.

The distribution of thyroid cancer by gender in our study was similar to other reports from other populations with a frequency three times higher in females compared with males. The higher frequency of medullary carcinoma among men in our study is not consistent with other reports that show medullary carcinoma occurs almost equally among males and females [24]. Further studies are needed to investigate this inconsistency.

The age distribution of thyroid cancer in our data showed two peaks of incidence, one for age group 45-60 and another peak after age 65 . The same distribution is seen in other populations except in areas of the world affected by the radiation from nuclear fallouts and nuclear accidents such as the Chernobyl accident area where the incidence of thyroid cancer has increased several times among younger age group due to exposure to the fallout of radioactive material, especially the iodine- 131 isotope [25]. A different age distribution between women and men in our data is again consistent with the data from other populations $[15,16]-$ a higher incidence is seen in women of reproductive age.

The observed survival rate of the population with thyroid cancer in Iran was high compared with the survival rate reported from the population-based registries in Chiang Mai, China [26] (where the 5-year survival rate was $48.3 \%$ ) and was comparable with the survival data from the cancer registry in Khon Kean, Thailand [26], (where the 5-year survival rate was $82.8 \%$ ). The rate observed in our study was lower than the survival rate reported from the USA (where the 5-year relative survival rate was reported to be $94.6 \%$ ) [27]. The survival rates are highly dependent on the stage of disease at the time of diagnosis. In Iran, $28.6 \%$ of patients are diagnosed at the stage with distant metastasis [28], while in USA it is only 5\% [27].

A significant difference in survival rates between the age groups less than 50 and over 50 in our study is con- 
sistent with a study [28] in which an inverse correlation was reported between survival experience and increasing age. This is attributed to the greater frequency of anaplastic and undifferentiated tumours, which occur at a later age and are associated with a low survival rate. Our data did not show statistically significant differences in the survival experience of patients with different morphologic features of the tumour, although there were more deaths among medullary and anaplastic cases. A lack of statistical significance for the survival function of different morphologic tumours is due to the low number of cases of medullary and anaplastic tumours in this study. In the survival analysis, we were unable to ascertain the survival status for nearly $50 \%$ of cases. This may be seen as a serious limitation in interpreting our results.

\section{Conclusion}

This study showed the descriptive epidemiology of thyroid cancer based on population data highlighting several similarities with other populations.

\section{References}

1 Franceschi S, La Vecchia C: Cancer of the thyroid; in Doll RI, Fraumeni JF Jr, Muir CS (eds): Trends in Cancer Incidence and Mortality. Cold Spring Harbor, Cold Spring Harbor Press, 1994, pp 393-424.

2 Franceschi S, Preston-Martin S, Dal Maso L, et al: A pooled analysis of case-control studies of thyroid cancer. IV. Benign thyroid diseases. Cancer Causes Control 1999; 10:583-595.

3 Parkin DM, Muir CS, Whelan SL, Gao YT, Ferlay J, Powell J: Cancer Incidence in Five Continents. Lyon, IARC, 1992, pp 146-147.

- 4 Mulla ZD, Margo CE: Primary malignancies of the thyroid: epidemiological analysis of the Florida cancer data system registry. Ann Epidemiol 2000; 10:24-30.

- 5 Christensen SB, Ljundberg O, Tibblin S: Thyroid carcinoma in Maloma, 1960-1977. Cancer 1984;53:1625-1633.

6 Ain KB: Papillary thyroid carcinoma. Endocrinol Metab Clin North Am 1995;24:711-760.

7 Ferich L, Akslen LA, Glattre E: Increased risk of thyroid cancer among Norwegian women married to fishery workers: a retrospective cohort study. Br J Cancer 1997;76:385-389.

8 Galanti MR, Ekbom A, Grimelius L, Yuen J: Parental cancer and risk of papillary and follicular thyroid carcinoma. Br J Cancer 1997; 75:451-456.

9 Salabe GB: Aetiology of thyroid cancer and epidemiological overview. Thyrology 1994;6: 11-19.

-10 Kimiagar M, Azizi F, Navai L, Yassai M, Nafarabadi T: Survey of iodine deficiency in a rural area near Tehran: association of food intake and endemic goiter. Eur J Clin Nutr 1990;44: 17-22.

11 Azizi F, Kimiagar M, Nafarabadi M: Current state of iodine deficiency in the Islamic Republic of Iran. EMR Health Survey 1990;8:2327.
12 Larijani B, Shirzad M, Mohagheghi MA, Haghpanah V, Mosavi-Jarrahi AR, Tavangar SM, Vassigh AR, Hossein-Nezhad A, Bandarian F, Jalili RB: Epidemiologic analysis of the Tehran Cancer Institute Data System Registry (TCIDSR). Asian Pac J Cancer Prev 2004;5:36-39.

13 Mohagheghi M, Moosavi JA, Shariat TS: Annual report of Tehran University of Medical Sciences District Cancer Registry. Tehran, 1998.

14 Mosavi-Jarrahi A, Mohagheghi MA, Atri M, Golmahi M: Developing best sets of information recorded in cancer registry database to search for duplicate and repeat management; in 23rd Annu Meet Int Assoc Cancer Registries, Havana, Oct 2001.

15 Al Jarallah M, Al Hamdan N: Gulf Center for Cancer Registration (GCCR). 2000 cancer incidence report. Riyadh, GCCR, 2003.

16 McCredie M, Coates M, Grulich A, Grulich A: Cancer incidence in migrants to New South Wales (Australia) from the Middle East, 19721991. Cancer Causes Control 1995;5:414421.

17 Azizi F, Navai L, Navai L, Fattahi F: Goiter prevalence, urinary iodine excretion, thyroid function and anti-thyroid function and antithyroid antibodies after 12 years of salt iodization in Shahriar, Iran. Int J Vitam Nutr Res 2002; 72:291-295.

18 Franceschi S, Fassina A, Talamini R, Mazzolini A, Vianello S, Bidoli E, Serraino D, La Vecchia C: Risk factors for thyroid cancer in North Italy. Int J Epidemiol 1989;18:578-584.

19 Franssila K, Saxen E, Teppo L, Bjarnason O, Tulinius H, Normann T, Ringertz N: Incidence of different morphological types of thyroid in Nordic countries. APMS 1981;89:49_ 55.
20 Bacher-Stier C, Riccabona G, Totsch M, Kemmler G, Oberaigner W, Moncayo R: Incidence and characteristic of thyroid carcinoma after iodine prophylaxis in an endemic goiter country. Thyroid 1997;7:733-741.

21 Ghiassi-Nejad M, Beitollahi M, Asefi M, RezaNejad F: Exposure to ${ }^{226} \mathrm{Ra}$ from consumption of vegetable in high level natural radiation areas of Ramsar, Iran. J Environ Radioact 2003; 66:215-225.

22 Mohammadi H, Tabeie F, Saghari M: Trends of population radiation absorbed dose from diagnostic nuclear medicine procedures in Iran: 1985-1989. Health Phys 1995;68:503-508.

23 Tavakoli MB: Annual radiation background in the City of Isfahan. Med Sci Monit 2003;9: PH7-PH10.

24 Ron E: Thyroid cancer; in Schottenfield D, Fraumeni JF (eds): Cancer Epidemiology and Prevention, ed 2. New York, Oxford University Press, 1996.

25 Tronko MD, Bogdanova TI, Komissarenko IV, Epstein OV, Oliynyk V, Kovalenko A, Likhtarev IA, Kairo I: Thyroid carcinoma in children and adolescents in Ukraine after the Chernobyl nuclear accidents: statistical data and clinicomorphologic characteristics. Cancer 1999;86:149-156.

26 Sankaranarayanan R, Black RJ, Parkin DM: Cancer Survival in Developing Countries. Lyon, International Agency for Research on Cancer, publication No 145, 1998.

27 Ries LAG, Miller BA, Hanky BF: SEER Cancer Statistics Review 1973-1991: tables and graphs. Bethesda, National Cancer Institute, publication No 94-2789.

28 Larijani B, Aghakhani S, Khajedini H, Baradar-Jalili R: Clinico-pathological features of thyroid cancer as observed in five referral hospitals in Iran; a review of 1,177 cases. Acta Oncol 2003;42:334-337. 